\title{
Assessment of Trend and Variability of Rainfall at Upper Seonath River Basin
}

\author{
Nidhi Suryavanshi ${ }^{1}$, Manish Kumar Sinha ${ }^{1}$, Sushmita Gouraha ${ }^{1}$ \\ ${ }^{1}$ Department of Environmental \& Water Resources Engineering., University Teaching Department, Chhattisgarh \\ Swami Vivekanand Technical University, Bhilai-491107, Chhattisgarh, India \\ Corresponding Author: Email id: nidhisurya233@gmail.com
}

\begin{abstract}
The quantitative analysis of the rainfall events is one of the significant techniques for effective management of hydrological system. Evaluating the spatial and temporal complexities of meteorological parameters in the perspective of climate transition, especially in countries where rain fed farming is predominant, is essential for assessing climate-induced changes and suggesting suitable management approaches. The variability of the annual rainfall has great implications for the planning of irrigation related projects and thus such studies are critical for the planning of agriculture in India. Agriculture is one of the important activities that are highly influenced by the variation of rainfall and temperature. This is an attempt to analyze one of the most significant climate variables i.e. precipitation, to analyze the trend in rainfall in the area. Rainfall variability can be calculated in many ways, both in terms of time and location. Evaluation of rainfall events can be helpful to identify the climatic condition of the particular region. The magnitude or variations of factors differs depending on wherever the area is located [1]. This study is an attempt to investigate about the spatio-temporal variability of rainfall at Upper Seonath basin. Mann-Kendall test has been used to analyze the trend in rainfall data at different gauging stations and the Sen's slope method has been used to determine the magnitude of the change [2]. Trend analysis is one of the active area of interest to investigate the rainfall variability over the years. Trend analysis for the observed rainfall series was undertaken using Mann-Kendall test. Innovative trend analysis was considered to be an effective method for detecting the overall trend of rainfall events [3]. Long term annual average rainfall and coefficient of variability at each station have been computed and Geographic Information System (GIS) has been used to represent the spatio-temporal variation of rainfall. Daily rainfall data of 34 years from 1980 to 2013 has been analysed in the study to find out the variability of rainfall. Trend analysis of rainfall events on yearly basis represents declining trend across the study region [4].
\end{abstract}

Keywords: Rainfall; Trend analysis; Mann-Kendall; GIS; Sen's slope.

\section{Introduction}

A major concern in recent years is climate change. Climate variability has recently been related to a significant number of fatalities such as typhoons, flooding, drought and wild fires [5]. Rainfall variation directly affects the feasibility of land for cultivation and crop production practices. This variation has major effects on the social practices and economic

activity of the country. Precipitation is the main climatic variable affecting the spatiotemporal water resources patterns [6]. Rainfall is the main aspect of any watershed that plays a major role in the extent of flooding, flood control and water management [7]. Analyzing the long-term patterns and variability of rainfall is 
extremely important for sustainable management in the resources of water. The time series-based shifts in the trend in precipitation are the temporal shift in rainfall patterns that can either fall or rise and this trend adjustment is the primary component of climate variations [8]. Trend analysis was done in the present study by applying the non-parametric Mann-Kendall test. This is a statistical method that is used to analyze the hydro-climatic sequence patterns in spatiotemporal variability. Consideration is given to a non-parametric test over the parametric one, since it can evade the data skew problem. If multiple stations are tested in a single study, Mann-Kendall testing is favored[2]. The MannKendall test was used to find any trend of rainfall, temperature and evapo-transpiration (both monthly and annually) that showed some meaningful results in case of rainfall, and the Sen's slope method was used to find out the magnitude of the change.

\section{Study Area}

The Seonath River originates near the village of Panabaras in the district of Rajnandgaon that is $624 \mathrm{~m}$ above sea level. The climatic condition of upper Seonath basin is hot and humid and this basin falls between $20^{\circ} 20^{\prime} \mathrm{N}$ to $22^{\circ} 40^{\prime} \mathrm{N}$ latitude and $80^{\circ} 20^{\prime} \mathrm{E}$ to $81^{\circ} 40^{\prime} \mathrm{E}$ latitude. This river basin area to the confluence with the river Mahanadi is $30.860 \mathrm{sqkm}$. The mean annual rainfall in this basin varies from 1005 mm-1255 $\mathrm{mm}$ and majority of it contributed by monsoon season i.e from June to October. The mean area annual temperature varies from $15^{\circ} \mathrm{C}$ to $21^{\circ} \mathrm{C}$. The length of the river is $380 \mathrm{~km}$. Seonath River's major tributaries are:- Tandula, Kharun, Arpa, Hamp, Agar, and Maniyari. The basin topography is plain.

\section{Materials and Methods}

The daily rainfall data of 18 Meteorological stations over Seonath river basin for period of 34 years (from 1980 to 2013) were collected from State Data Centre, Water Resources Department, Raipur, Chhattisgarh and Central Water Commission (CWC), Bhubaneswar, for the variability test of annual rainfall of these 18 stations (Ambagarh-Chowki, Anda, Balod, Chuikhadan, Doundi, Doundilohara, Dongargarh, Dongargaon, Dhamdha, Durg, Gondly, Kharkhara, Khapri, Kotni, Gunderdehi, Madiyan, Tandula-Vinayakpur and Seonath-singdai) with respect to space and time.

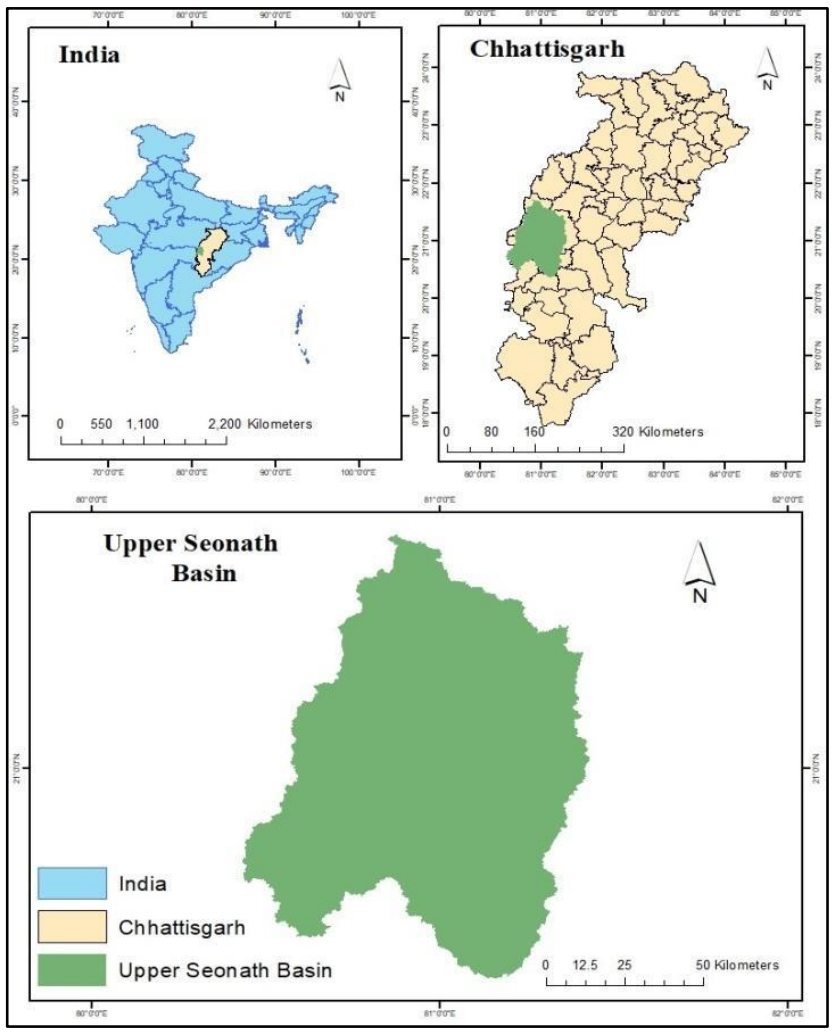

Fig1. Location map of Upper Seonath basin 


\section{Trend Analysis}

Statistically, the trend is a substantial change over time, calculated by parametric and nonparametric methods, whereas trend analysis of a time series consists of a trend magnitude and its statistical significance [4].

Trend is characterized as the common shift of a series over a longer time period [9]. This method is a statistical methodology that makes use of past findings to predict future outcomes. In statistics, trend analysis also refers to methodology to derive an underlying behavior pattern in a time series and if patterns have shapes other than linear, non-parametric methods such as: Mann-Kendall test, which is a variant of the Kendall rank correlation coefficient, can be used to analyze trends.

\section{Mann Kendall Test}

Mann-Kendall method is used to analyze data collected over time to steadily increase and decrease patterns. It is a non-parametric test, meaning it can work on all distributions but there should be no serial correlation between results. How it works:-

- The Null hypothesis for this test is that, there is no trend in the series.

- The Alternate hypothesis is that, a trend exists. This can be positive, negative or nonnull.

Before performing Mann Kendall test, we must ensure about the following points:-

i. This test is usually used for data obtained seasonally. If up and down trends exist in the data, the test will not work.

ii. There should no covariates in your data.

iii. Just use median value, if you are having numerous points or value. Either you must have single data set for each period of time.

Statistical Mann-Kendall test is used for trend analysis of the Hydrological time series. The use of the Mann-Kendall method has two benefits. Firstly, MannKendall is a nonparametric test which does not require the data to be distributed normally. Secondly, Mann-Kendall test has low sensitivity to abrupt breaks due to non-homogenous time series. MannKendall test checks the null Hypothesis Ho of no trend (data is independent and randomly ordered) against the alternative Hypothesis $\mathrm{H}_{1}$ of increasing or decreasing trend. For this test the computational procedure considers time series of $n$ data points also $\mathrm{x}_{\mathrm{j}}$ and $\mathrm{x}_{\mathrm{k}}$ are two subsets of data where $\mathrm{j}=1,2,3,4, \ldots . ., \mathrm{n}-1, \mathrm{k}=\mathrm{j}+1$, $\mathrm{j}+2, \ldots \ldots, \mathrm{n}$. The data values are estimated as a systematic time series. A data value is compared to all succeeding data values. For analysis of data values, the initial value of Mann-Kendall test statistic ' $\mathrm{S}$ ' is assumed to be zero (i.e. no trend). If the data value from a later time period is higher than a data value from an earlier time period, the test statistic ' $\mathrm{S}$ ' is incremented by 1 . On the other hand, if the data value sampled earlier, ' $S$ ' is decremented by 1 . The net result of all such increments and decrements yields the final value of ' $\mathrm{S}$ '.

Let $\mathrm{x}_{1}, \mathrm{x}_{2}, \mathrm{x}_{3}, \ldots . . \mathrm{x}_{\mathrm{n}}$ are $\mathrm{n}$ data points, where $x_{j}$ is the data point at time $j$. Then Mann-Kendall test statistic (S) 


$$
\begin{gathered}
S=\sum_{k=1}^{n-1} \sum_{j=i+1}^{n} \operatorname{sign}\left(x_{j}-x_{k}\right) \\
\operatorname{Sign}\left(x_{j}-x_{k}\right)=\left\{\begin{array}{c}
+1 \ldots \ldots \ldots \ldots, x_{j}-x_{k}>0 \\
0 \ldots \ldots \ldots \ldots, x_{j}-x_{k}=0 \\
-1 \ldots \ldots \ldots \ldots \ldots, x_{j}-x_{k}<0
\end{array}\right\}
\end{gathered}
$$

Where, $x \mathrm{j}$ and $\mathrm{xk}=$ annual values in years $\mathrm{j}$ and $\mathrm{k}$.

A positive $\mathrm{S}$ value implies rising trend, and a declining trend is shown by the negative $\mathrm{S}$ value.

For $\mathrm{n}<10$, the two-tailed test is used, the value of $\mathrm{S}$ is compared to the theoretical distribution of $\mathrm{S}$ which is derived from Mann-Kendall[2]. Null hypothesis Ho is rejected in favor of $\mathrm{H} 1$ if the absolute value of statistics equals or greater than referenced value $S \alpha / 2$, appear in case of no trend where $\mathrm{S} \alpha / 2$ is smallest $\mathrm{S}$ which has the probability less than $\alpha / 2$. ....For $n \geq 10$, the test statistic $S$ is approximately normally distributed with zero mean and variance.

\section{Sen's Estimator Method}

For predicting the magnitude of change (true slope) of hydro-meteorological time series data, Sen's slope nonparametric estimator method has been used. For the analysis of trends, the Sen's slope estimator uses a linear model. From the below equation the slope $\left(\mathrm{T}_{\mathrm{i}}\right)$ of all data pairs is calculated.

For $\mathrm{i}=1,2,3, \ldots \ldots \ldots$.

$$
T i=\frac{X j-X k}{j-k}
$$

Where, $\mathrm{Xj}$ and $\mathrm{X}_{\mathrm{k}}$ are data values at time $\mathrm{j}$ and $\mathrm{k}$ $(j>k)$ separately. The median of these $n$ values of $T_{i}$ is represented by Sen's slope of estimation (true slope) which is calculated using the below equation.

$$
Q i=\frac{T n+1}{2}
$$

When, $\mathrm{n}$ is odd

$$
Q i=\frac{1}{2}\left(\frac{T n}{2}+\frac{T n+2}{2}\right)
$$

When $\mathrm{n}$ is even Sen's estimator (Qmed) is calculated using the above equation based on the value of $n$ being either odd or even and Qmed is then calculated using 100(1$\alpha)$ percent confidence interval using nonparametric testing depending on the normal distribution. A positive Qi value indicates a rising (upward) trend while a negative Qi value reflects a declining (downward) trend in time series data[4].

\section{Results and Discussion}

The precipitation and temperature are the most important climatic factors in the study region because greater than $80 \%$ of agricultural production depends on rainfall. In this study, trend analysis of rainfall of 18 meteorological stations was done with the help of Mann-Kendall test and Sen's slope estimator for 34 years of data (1980-2013) annually.

The minimum rainfall recorded in this time series is at Chhuikhadan station and maximum recorded rainfall was at Durg station. The result of spatial and temporal distribution of annual rainfall is found out by MK test and trends at $95 \%$ confidence level in upper Seonath basin is shown in the graphs. The $\mathrm{Z}$ value is calculated from MK test and Q is calculated from Sen's slope estimator of every station on a yearly basis. 

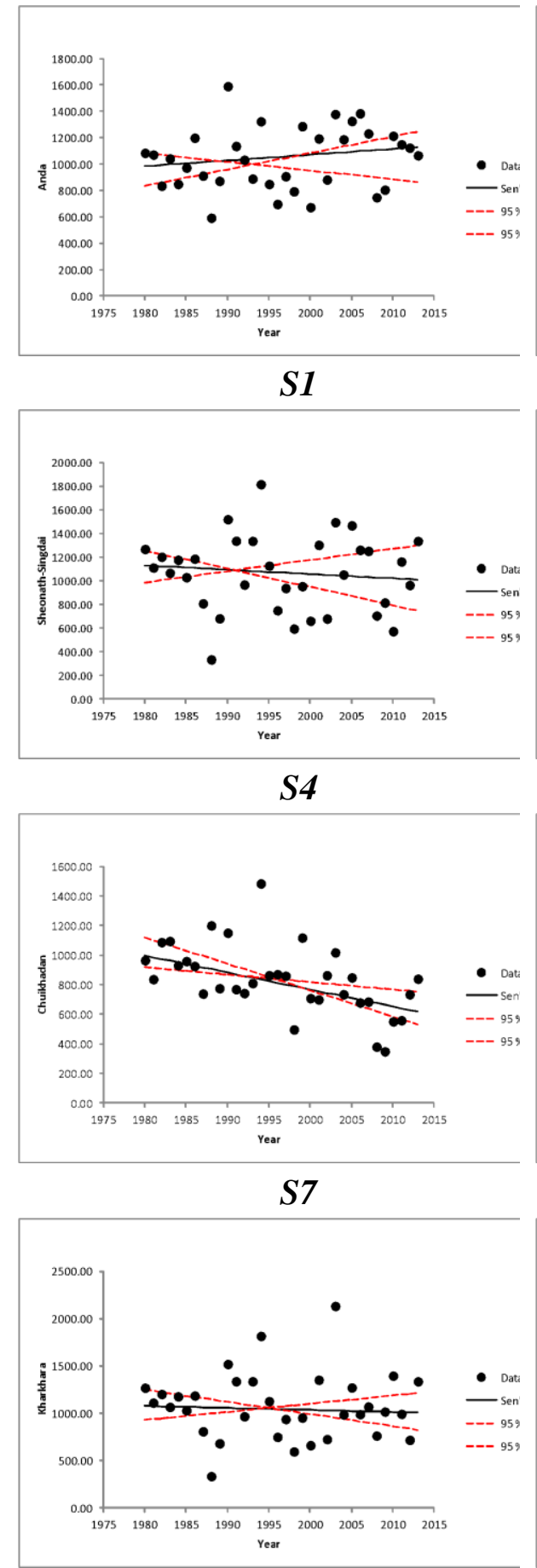

S10

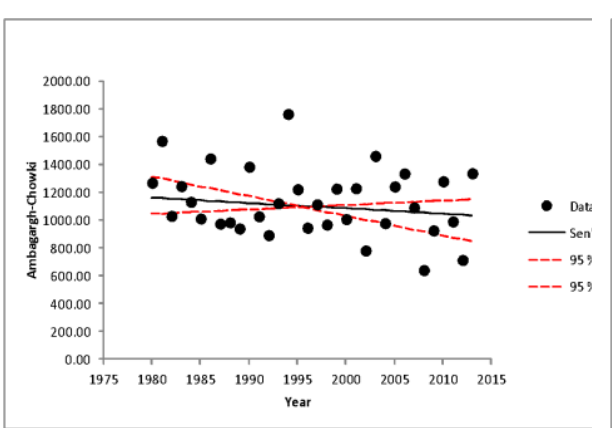

\section{S2}

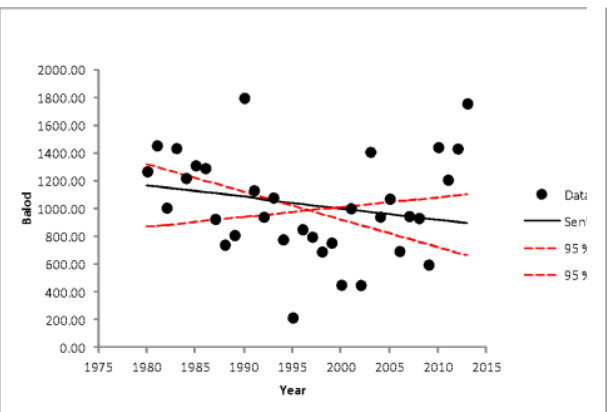

\section{S5}

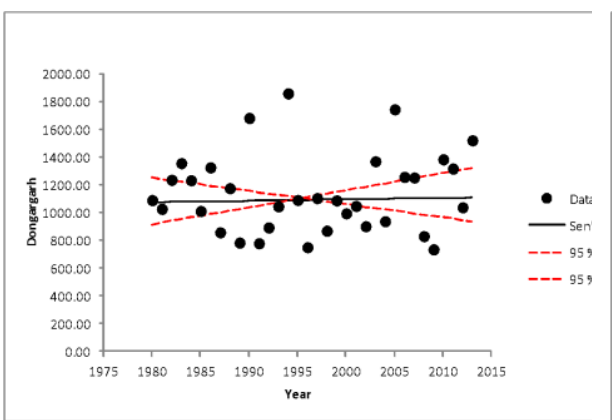

S8

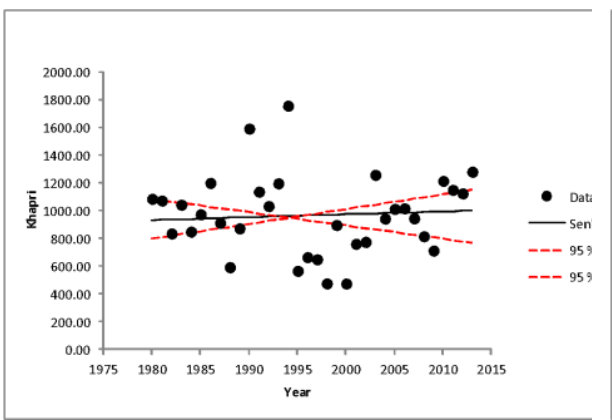

S11

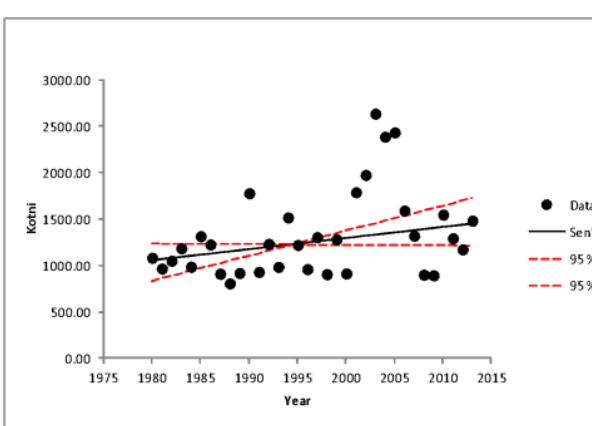

S3

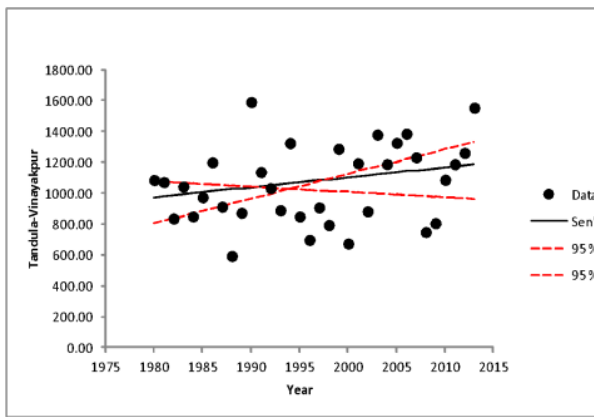

S6

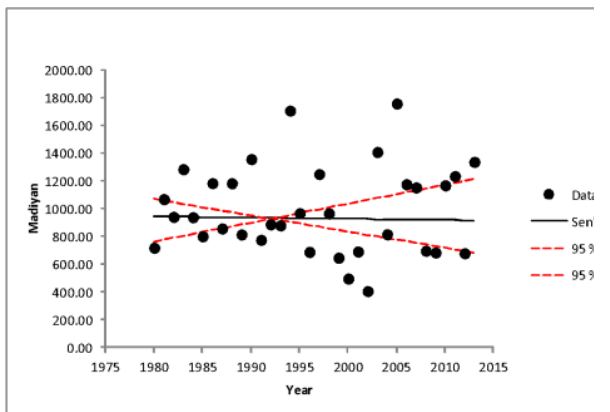

S9

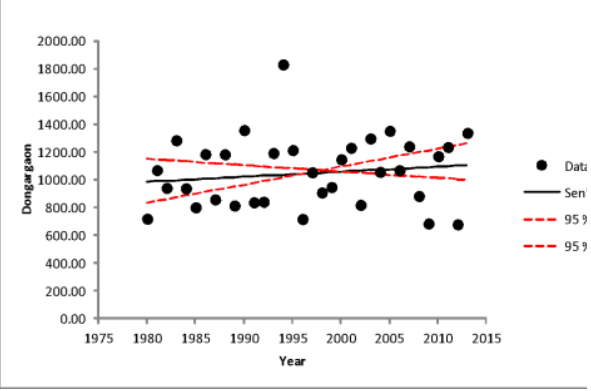

S12

136 CSVTU Research Journal 2020, Vol. 09, No. 2 


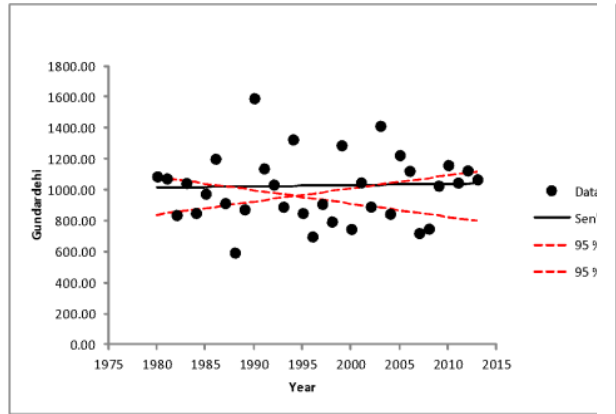

$S 13$

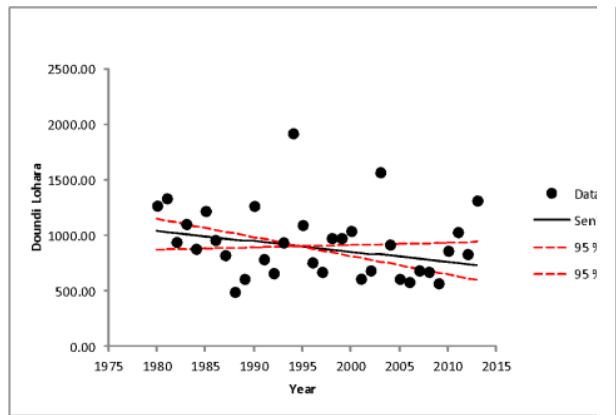

$S 16$

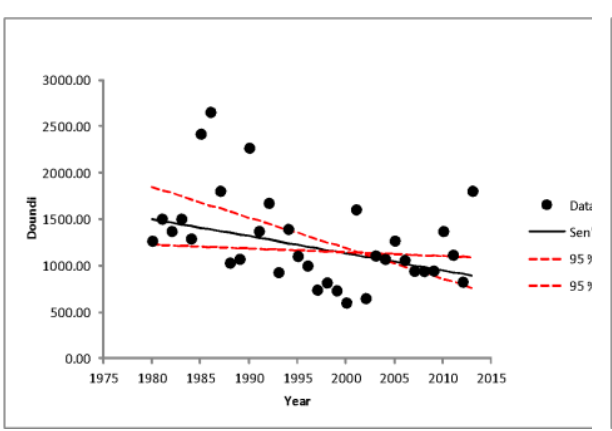

$S 14$

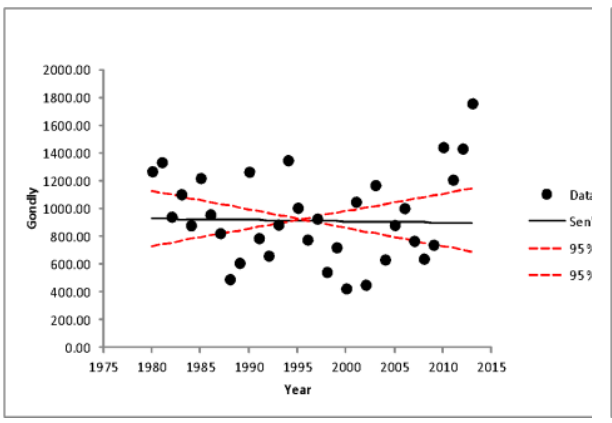

$S 17$

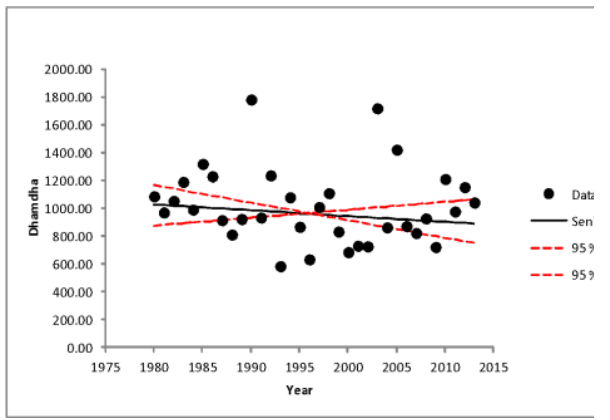

$S 15$

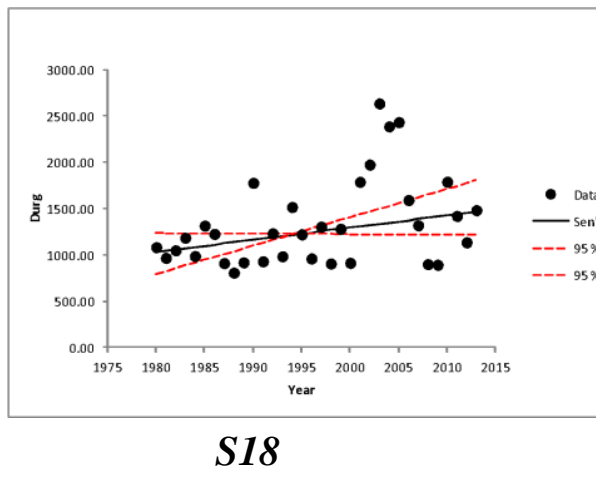

Fig 2 Annual rainfall trend at $95 \%$ confidence interval of various stations

Table 1 Trend Analysis for humid zone of various stations

\begin{tabular}{|c|c|c|c|c|c|c|c|}
\hline \multirow[b]{2}{*}{ SN. } & \multirow{2}{*}{$\begin{array}{l}\text { Name of } \\
\text { Stations }\end{array}$} & \multicolumn{3}{|c|}{ Mann-Kendall Test } & \multirow{2}{*}{$\begin{array}{c}\text { Rainfall } \\
\text { (mm) }\end{array}$} & \multicolumn{2}{|c|}{ Sen's Slope Estimate } \\
\hline & & First year & Last year & Test Z & & $\begin{array}{c}\text { Significa } \\
\text { nce }\end{array}$ & Q (mm/year) \\
\hline S1 & Anda & 1980 & 2013 & 0.80052 & 984.3667 & & 4.383333 \\
\hline $\mathrm{S} 2$ & $\begin{array}{l}\text { Ambagargh- } \\
\text { Chowki }\end{array}$ & 1980 & 2013 & -1.12666 & 1161.956 & & -3.88889 \\
\hline S3 & Kotni & 1980 & 2013 & 1.719635 & 1053.545 & & 11.92381 \\
\hline S4 & $\begin{array}{l}\text { Sheonath- } \\
\text { Singdai }\end{array}$ & 1980 & 2013 & -0.62263 & 1130.583 & $*$ & -3.66667 \\
\hline S5 & Balod & 1980 & 2013 & -0.94876 & 1165.565 & & -8.12964 \\
\hline S6 & $\begin{array}{l}\text { Tandula- } \\
\text { Vinayakpur }\end{array}$ & 1980 & 2013 & 1.363849 & 975.4167 & & 6.366667 \\
\hline S7 & Chuikhadan & 1980 & 2013 & -3.54343 & 997.2143 & & -11.4524 \\
\hline
\end{tabular}

137 CSVTU Research Journal 2020, Vol. 09, No. 2 


\begin{tabular}{|l|l|c|c|c|c|c|c|}
\hline S8 & Dongargarh & 1980 & 2013 & 0.296489 & 1074.88 & $* * *$ & 1.01 \\
\hline S9 & Madiyan & 1980 & 2013 & -0.26684 & 944.1217 & & -0.87391 \\
\hline S10 & Kharkhara & 1980 & 2013 & -0.38544 & 1078.874 & & -2.13524 \\
\hline S11 & Khapri & 1980 & 2013 & 0.26684 & 932.2381 & & 2.047619 \\
\hline S12 & Dongargaon & 1980 & 2013 & 0.919115 & 985.2924 & & 3.601053 \\
\hline S13 & Gundardehi & 1980 & 2013 & 0.207542 & 1013.88 & & 0.804 \\
\hline S14 & Doundi & 1980 & 2013 & -2.31261 & 1499.875 & & -18.38 \\
\hline S15 & Dhamdha & 1980 & 2013 & -0.83017 & 1026.986 & $*$ & -4.1835 \\
\hline S16 & Doundi Lohara & 1980 & 2013 & -1.52709 & 1038.5 & & -9.2 \\
\hline S17 & Gondly & 1980 & 2013 & -0.14824 & 927.1 & & -0.93333 \\
\hline S18 & Durg & 1980 & 2013 & 1.897529 & 1032.336 & & 13.17143 \\
\hline
\end{tabular}

$* * *=0.001$ significance level $\quad *=0.05$ significance level

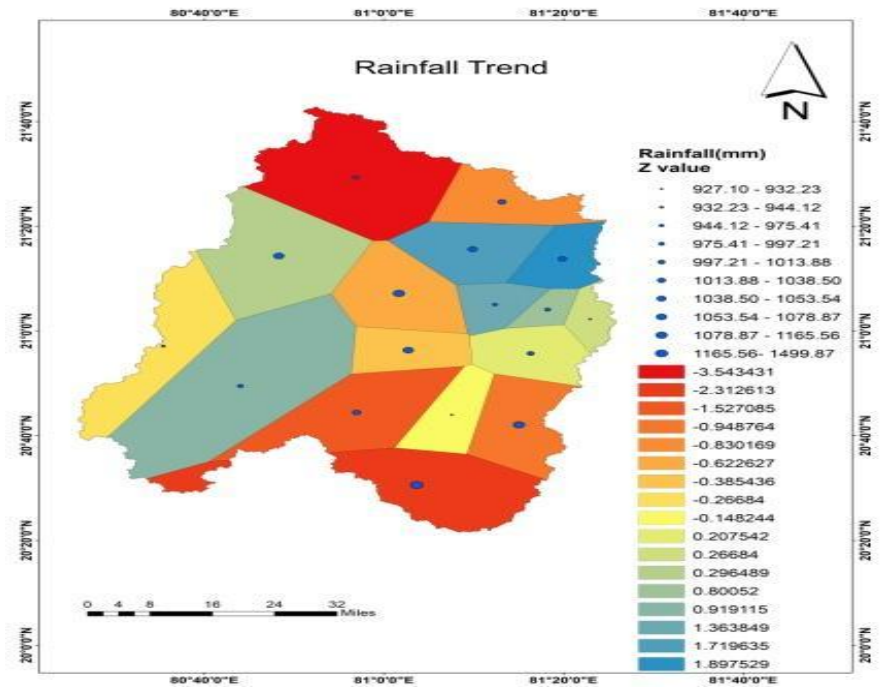

Fig 3 Spatio-temporal annual rainfall trend and values of $z$ static of the study area.

\section{Conclusion}

Imbalances or changes in climatic conditions are a common occurrence in the districts studied. In this analysis, the annual variability of rainfall for 18 representative meteorological stations in Chhattisgarh Regional State was analyzed. For the analysis, the temporal pattern of rainfall was also determined. Annual rainfall variation was investigated in all stations. Increasing trends have been observed in stations namely Durg, Anda, Dongargarh, Dongargaon, Khapri, Kotni, Gunderdehi, and Tandula-Vinayakpur, while stations such as Ambagarh-Chowki, Balod, Chuikhadan, Doundi, Doundilohara, Dhamdha, Kharakhara, Mandiyan, and Seonath-singdai are showing decreasing trends. The results of Mann-

Kendall, slope estimator test by Sen and the trend were compatible. Therefore, stakeholders should more concern towards the variability of rainfall of the region and its impact on economy. And proper mitigation strategy must follow to overcome the impact of climate change.

\section{Acknowledgment}

We are greatly thankful to Indian Meteorological Department of Raipur, State Data Centre, Water 
Resources Department, Raipur, Chhattisgarh and Central Water Commission (CWC), Bhubaneswar, for providing required data. Research hub and library of CSVTU Bhilai would be surely acknowledged for their prompt response and availability of facilities.

\section{Conflict of Interest}

The authors declare no conflict of interest.

\section{Reference}

[1] R. B. Singh, N. Rathore, P. Mishra, U. Singh, S. K. Pysai, and A. Dubey, "Rainfall variability analysis of Rewa district in Madhya Pradesh," vol. 8, no. June, pp. 7477, 2019.

[2] A. Mondal, S. Kundu, and A. Mukhopadhyay, "Case Study Rainfall Trend Analysis by MANN-KENDALL TEST : A Case Study of North-Eastern Part of Cuttack District , Orissa School of Oceanographic Studies , Jadavpur University , Kolkata700032 * Author for Correspondence Case Study Trend Analysis," vol. 2, no. 1, pp. 70 78, 2012.

[3] H. Tiwari and B. K. Pandey, "Nonparametric characterization of long-term rainfall time series," Meteorol. Atmos. Phys., vol. 131, no. 3, pp. 627-637, 2019, doi: 10.1007/s00703-018-0592-7.

[4] S. Chakraborty, R. P. Pandey, U. C. Chaube, and S. Mishra, "Trend and variability analysis of rainfall series at Seonath River Basin, Trend and variability analysis of rainfall series at Seonath River Basin, Chhattisgarh ( India )," no. January, 2013, doi: 10.6088/ijaser.020400005.

[5] R. Granados, J. Soria, and M. Cortina, "Rainfall variability, rainfed agriculture and degree of human marginality in North Guanajuato, Mexico," Singap. J. Trop. Geogr., vol. 38, no. 2, pp. 153-166, 2017, doi: 10.1111/sjtg.12191.

[6] H. R, S. J, and S. R, "Techniques of trend analysis for monthly water quality data," Water Resour. Res., vol. 18, no. 1, pp. 107121, 1982.

[7] A. Abiyu and D. Batsuren, "Innovative Trend Analysis of Annual and Seasonal Rainfall Variability in Amhara Regional," doi: 10.3390/atmos9090326.

[8] Shahid, S., \& Khairulmaini, O. S. (2009). Climatic change due to global warming is a major concern in the recent years. It has been indicated that rainfall is changing due to global warming on both the global (Hulme. Asia-Pacific Journal of Atmospheric Sciences, 375-389.

[9] A. Asfaw, B. Simane, A. Hassen, and A. Bantider, "Variability and time series trend analysis of rainfall and temperature in northcentral Ethiopia: A case study in Woleka sub-basin," Weather Clim. Extrem., vol. 19, no. June, pp. 29-41, 2018, doi: 10.1016/j.wace.2017.12.002.

[10] Karpouzos, D.K. and Kavalieratau, S. (2010) Trend analysis of precipitation data in Piera region (Greece). European Water, 30(30), $30-40$. 